\title{
Lung function abnormalities and decline of spirometry in scleroderma: an overrated danger?
}

\author{
M.J. Abramson, A.J. Barnett ${ }^{1}$, G.O. Littlejohn², M.M. Smith ${ }^{1}$ and S. Hall1,3 \\ Department of Social and Preventive Medicine, Monash Medical School, Alfred Hospital, Prahran, \\ Victoria 3181, ${ }^{1}$ Alfred Hospital, Melbourne, ${ }^{2}$ Monash Medical Centre, Melbourne and ${ }^{3}$ Box Hill Hospital, \\ Melbourne, Australia
}

\begin{abstract}
Summary: To document the prevalence and progression of pulmonary involvement in scleroderma (systemic sclerosis including the CREST syndrome), the clinical notes and lung function records of 113 cases were reviewed. Lung function was normal in 39 cases, isolated impairment of $D_{L} C O$ was found in 38 patients, a restrictive defect was present in 27 cases and there was evidence of airflow obstruction in 9 cases. The median duration of symptoms was 10 years. Dyspnoea and an interstitial pattern on chest $X$-ray were associated with impaired lung function. Death during the period of review was significantly related to initial impairment of the $D_{L} C O$. Sixty-six patients $(53$ women and 13 men) underwent repeat spirometry at least 1 year after initial testing. The rates of change in $V C$ and $F E V_{1}$ were no more rapid than would be expected for normal subjects. There was no significant difference in rates of change between men and women or between dyspnoeic patients and those who were asymptomatic. The extent of skin involvement and the presence of interstitial fibrosis on chest $\mathrm{X}$-ray were unrelated to the rate of loss of lung function. It is concluded that most scleroderma patients in this study had abnormal lung function when first tested, but overall significant worsening of spirometry was not found.
\end{abstract}

\section{Introduction}

Scleroderma (systemic sclerosis including the CREST syndrome of Calcinosis, Raynaud's phenomenon, Oesophageal dysmotility, Sclerodactyly and Telangiectasia) is known to be associated with impaired gas diffusion and restrictive lung disease. ${ }^{1,2}$ Whilst pulmonary involvement has been long shown to be associated with reduced survival, ${ }^{3}$ its nature and progression has generally been inferred from small series of cases. ${ }^{2,4}$ Colp et al. ${ }^{5}$ found less rapid decline of lung function in scleroderma than in idiopathic pulmonary fibrosis. Pulmonary fibrosis and/or pulmonary hypertension also result in impaired survival. ${ }^{6}$ Pulmonary hypertension can be noninvasively predicted with $75 \%$ accuracy from the combination of reduced diffusing capacity of the lung for carbon monoxide $\left(\mathrm{D}_{\mathrm{L}} \mathrm{CO}\right)$ below $43 \%$ predicted and characteristic chest X-ray and electrocardiograph findings. ${ }^{7}$ It has been suggested that impaired $D_{L} C O$ is by itself an adverse prognostic factor ${ }^{8}$ and that that treatment with D-penicillamine may improve the $D_{L} C O{ }^{9}$ To address these questions, a case series drawn from two hospitals was reviewed.

Correspondence: M.J. Abramson, M.B., B.S., Ph.D., F.R.A.C.P.

Accepted: 5 February 1991

\section{Methods}

The clinical notes and lung function records of 113 cases of scleroderma were reviewed. Diagnosis was made on the basis of ischaemia of the extremities plus bilateral symmetrical skin stiffness. Seventytwo of these cases were drawn from a series of 177 patients followed during a period of 30 years by one author (AJB) and last reviewed in 1984. All patients who had at least one pulmonary function test, generally performed at presentation, were included. Other characteristics of that series have been reported elsewhere. ${ }^{10}$ Forty-one subjects were patients of the other authors who interviewed and retested them specifically for this study in 1985 . Dyspnoea was graded as being present at rest or on exertion. Cough was graded as being dry or productive. All but 6 patients were followed up to 31st December 1985 or death.

Unforced vital capacity (VC) and forced expiratory volume at one second $\left(\mathrm{FEV}_{1}\right)$ were measured by Godart water sealed spirometers or other spirometers which were regularly shown to give similar results. Prior to the administration of bronchodilator, the best of three $\mathrm{VC}$ and $\mathrm{FEV}_{1}$ reproducible to within $50 \mathrm{ml}$ or $3 \%$ of the reading, whichever was the greater, were recorded following American Thoracic Society standards. ${ }^{11}$ The 
diffusing capacity of the lung for carbon monoxide $\left(D_{L} C O\right)$ was measured by the standard single breath method with breath-holding. ${ }^{12}$ The diffusing coefficient $(\mathrm{KCO})$ was estimated as the $\mathrm{D}_{\mathrm{L}} \mathrm{CO} /$ alveolar volume $\left(V_{A}\right)$. Predicted values for lung function variables were calculated for sex, age and height using published equations. ${ }^{12}$

Anti-nuclear antibody was detected by immunofluorescence against HEp-2 cell substrates which showed various patterns including centromere staining. Chest X-rays had previously been reported independently without knowledge of lung function results. The data were entered on a microcomputer and subsequently analysed by the MINITAB statistical package ${ }^{13}$ on a VAX mainframe computer. The duration of Raynaud's phenomenon was log transformed to normalize its distribution. The statistical tests employed included chi-squared, Student's $t$-test, Mann-Whitney test, analysis of variance, Kruskall-Wallis test and Pearson's product-moment correlation. ${ }^{14}$

\section{Results}

\section{Clinical data}

The 113 cases comprised 91 women and 22 men. The mean age when first tested was 50.6 years, the standard deviation (s.d.) 14 years and the range was from 16 to 81 years. The median duration of Raynaud's phenomenon was 10 years and the maximum duration 60 years. The extent of skin involvement at presentation was categorized as previously described. ${ }^{10}$ Fifty-seven patients had sclerodactyly, i.e. skin changes in the fingers only (Type 1), 40 patients had skin changes beyond the fingers but confined to the extremities and face (Type 2) and 11 patients had diffuse skin changes involving the trunk (Type 3). The degree of skin involvement was not recorded in 5 cases. Fortyeight patients ( $49 \%$ of those asked) complained of dyspnoea on exertion, 6 of dyspnoea at rest, 20
( $24 \%$ of those asked) admitted to dry cough and 10 $(12 \%)$ to productive cough. Smoking status was recorded for 72 patients: $41(57 \%)$ were nonsmokers, $17(24 \%)$ were ex-smokers and $14(19 \%)$ were current smokers at presentation.

Twenty-one patients ( $24 \%$ of those known) had received D-penicillamine between initial and repeat testing. Chest X-rays were performed on 80 patients: $46(58 \%)$ were reported as normal, 16 $(20 \%)$ showed an interstitial linear/reticular pattern, $8(10 \%)$ had cardiac failure, and $10(12 \%)$ had unrelated abnormalities. The presence of an interstitial pattern was associated with dyspnoea $\left(\chi^{2}=7.21, P<0.01\right)$. Anti-nuclear antibody (ANA) was detected at titre of $1: 40$ or greater in 73 cases or $82 \%$ of those tested. Anti-centromere antibody (ACA) was present in 32 or $52 \%$ of those tested. Only 6 patients were lost to follow-up and 24 were known to have died prior to 31st December 1985.

\section{Analysis of initial lung function}

The descriptive statistics for each lung function variable on initial testing are presented in Table I. Most of the 113 cases had abnormalities on initial lung function testing. Only 39 cases were normal (vital capacity (VC) $>80 \%$ predicted value, $\mathrm{FEV}_{1} /$ VC $>70 \%, D_{L} C O>80 \%$ predicted value). Impairment of $\mathrm{D}_{\mathrm{L}} \mathrm{CO}$ to below $80 \%$ of the predicted value was the sole abnormality in 38 cases. There was a predominantly restrictive defect (VC $<80 \%$ predicted value) in 27 cases and evidence of predominant aifflow obstruction $\left(\mathrm{FEV}_{1} / \mathrm{VC}<\right.$ $70 \%$ ) in 9 cases.

Tables II and III show the initial lung function variables in relation to clinical and radiological features. In some cases fewer than 113 subjects are listed because of missing information. Dyspnoeic patients had worse lung function than those who were asymptomatic (Table II). Analysis revealed significant differences for VC, $\mathrm{FEV}_{1}, \mathrm{D}_{\mathrm{L}} \mathrm{CO}$ and $\mathrm{KCO}$ expressed as \% predicted values between

Table I Description of lung function variables on initial testing

$$
(n=113)
$$

\begin{tabular}{lcccc}
\hline & $V C \%$ & $\begin{array}{c}F E V_{1} \% \\
\% \text { predicted value }\end{array}$ & $\begin{array}{c}D_{L} C O \% \\
\text { KCO\% }\end{array}$ \\
\hline Mean & 91 & 92 & 74 & 80 \\
Standard deviation & 20 & 19 & 20 & 19 \\
Minimum & 44 & 41 & 19 & 30 \\
Maximum & 145 & 137 & 133 & 132 \\
\hline
\end{tabular}

$\mathrm{VC}=$ vital capacity $\mathrm{FEV}_{1}=$ forced expiratory volume at 1 second; $\mathrm{D}_{\mathrm{L}} \mathrm{CO}=$ Diffusing capacity for carbon monoxide; $\mathrm{KCO}=$ Diffusing coefficient $\left(\mathrm{D}_{\mathrm{L}} \mathrm{CO} /\right.$ alveolar volume). 
Table II Comparison of mean initial lung function variables between asymptomatic patients, those with exertional dyspnoea and those with dyspnoea at rest

\begin{tabular}{|c|c|c|c|c|c|}
\hline \multirow{4}{*}{$\begin{array}{l}\text { Asymptomatic } \\
\text { Exertional dyspnoea } \\
\text { Resting dyspnoea }\end{array}$} & \multirow{2}{*}{$\begin{array}{c}n \\
43\end{array}$} & \multicolumn{2}{|c|}{$\begin{array}{c}V C \% \quad F E V_{1} \% \\
\% \text { predicted }\end{array}$} & \multicolumn{2}{|c|}{$\begin{array}{c}D_{L} C O \% \quad K C O \% \\
\% \text { predicted }\end{array}$} \\
\hline & & 100 & 99 & 83 & 85 \\
\hline & 48 & 86 & 88 & 71 & 80 \\
\hline & 6 & 80 & 75 & 58 & 59 \\
\hline $\begin{array}{r}\text { ANOVA - F } \\
\qquad<\end{array}$ & & $\begin{array}{c}7.8 \\
0.005\end{array}$ & $\begin{array}{c}6.6 \\
0.005\end{array}$ & $\begin{array}{c}7.3 \\
0.005\end{array}$ & $\begin{array}{c}4.1 \\
0.025\end{array}$ \\
\hline
\end{tabular}

For abbreviations see Table I.

Table III Comparison of mean initial lung function variables by chest $\mathrm{X}$-ray appearance.

\begin{tabular}{|c|c|c|c|c|c|}
\hline Chest $X$-ray & $n$ & $V C \%$ & $\begin{array}{c}F E V_{1} \% \\
\%\end{array}$ & $\begin{array}{l}D_{L} C O \% \\
\text { licted }\end{array}$ & $\mathrm{KCO} \%$ \\
\hline $\begin{array}{l}\text { Normal } \\
\text { Interstitial } \\
\text { CCF } \\
\text { Other }\end{array}$ & $\begin{array}{r}46 \\
16 \\
8 \\
10\end{array}$ & $\begin{array}{l}98 \\
78 \\
83 \\
93\end{array}$ & $\begin{array}{l}97 \\
81 \\
82 \\
88\end{array}$ & $\begin{array}{l}83 \\
60 \\
58 \\
75\end{array}$ & $\begin{array}{l}85 \\
69 \\
66 \\
84\end{array}$ \\
\hline $\begin{array}{r}\text { ANOVA - F } \\
P<\end{array}$ & & $\begin{array}{c}5.3 \\
0.005\end{array}$ & $\begin{array}{c}3.4 \\
0.05\end{array}$ & $\begin{array}{c}5.7 \\
0.005\end{array}$ & $\begin{array}{c}4.3 \\
0.01\end{array}$ \\
\hline
\end{tabular}

$\mathrm{CCF}=$ congestive cardiac failure; for other abbreviations see Table I.

asymptomatic patients and those with dyspnoea on exertion or at rest. $D_{\mathrm{L}} \mathrm{CO}$ expressed as $\%$ predicted was significantly lower in subjects reporting dry or productive cough (mean $68 \%$ and $71 \%$ ) than those without cough (mean $80 \%, P<0.05$ ). There were no significant correlations between the duration of Raynaud's phenomenon and VC, $\mathrm{FEV}_{1}, \mathrm{D}_{\mathrm{L}} \mathrm{CO}$ or KCO.

Patients with normal chest $\mathrm{X}$-rays had significantly better lung function than those with an interstitial pattern or other abnormalities (Table III). The extent of skin involvement, smoking and ANA were unrelated to $\mathrm{VC}, \mathrm{FEV}_{1}, \mathrm{D}_{\mathrm{L}} \mathrm{CO}$ or $\mathrm{KCO}$. Values of VC and FEV 1 expressed as per cent of predicted were significantly higher in patients who were anti-centromere antibody (ACA) positive (mean $99 \%$ compared with $88 \%, P<0.05$ ). There were no differences in gas transfer between the two groups. Subsequent vital status was unrelated to spirometry, but those who subsequently died did have significantly impaired $\mathrm{D}_{\mathrm{L}} \mathrm{CO} \%$ and $\mathrm{KCO} \%$ (mean $58 \%$ and $64 \%$ respectively) compared with those known to be living at the end of the review period (mean $79 \%$ and $88 \%, P<0.0001$ ).

\section{Changes in lung function}

Changes in spirometry were examined for the 66 patients ( 53 women, 13 men) who were followed for at least 1 year (mean $4.9,95 \%$ confidence interva $4.2-5.6$ years). Forty ( $59 \%$ ) had been followed for at least 4 years. The mean absolute decline in VC was $177 \mathrm{ml}(95 \%$ CI $77-277 \mathrm{ml})$ and that in FEV $161 \mathrm{ml}(95 \%$ CI $81-240 \mathrm{ml})$. Dividing by the interval between tests gave a mean rate of decline for VC of $38 \mathrm{ml} /$ year $\left(95 \%\right.$ CI 9-68 ml/year) and $\mathrm{FEV}_{1}$ of $29 \mathrm{ml} /$ year (95\% CI 5-53 ml/year). These do not differ significantly from the expected annual decline of $30 \mathrm{ml} /$ year in each parameter from cross-sectional data. ${ }^{12}$ Expressing the results as percentages of baseline values, the mean rate of decline in both VC and $\mathrm{FEV}_{1}$ was $1.0 \%$ /year.

There was no significant difference in annual rates of change in lung function variables between males and females. The duration of Raynaud's phenomenon did not correlate with the rate of change in $\mathrm{FEV}_{1}$, but there was a weak negative relationship with the rate of change in VC ( $r=$ $-0.30, P<0.05)$. Skin type, dyspnoea, cough, chest X-ray appearance, ANA and ACA were unrelated to the rates of change. The rates of change did not differ between those who lived and those who died.

Nineteen patients had more than two lung function tests. One patient had wide variation in lung function over short periods of time consistent with asthma. To assess rate of change more accurately, a regression was performed for change 
in $\mathrm{FEV}_{1}$ against years since first test (Figure 1). After deletion of outlying measurements, the slope coefficient for $\mathrm{FEV}_{1}$ was a decrease of $37 \mathrm{ml} /$ year, significantly different from zero $(t=6.17$, $P<0.0001)$. Dividing the difference between first and last measurements of $F E V_{1}$ for each subject by the time period between them appeared to overestimate the rate of change. However, the mean value for the 19 subjects of $55 \mathrm{ml} /$ year did not differ significantly from the slope of the regression line $(37 \mathrm{ml} /$ year, $t=1.21, \mathrm{NS})$ or the expected $30 \mathrm{ml} /$ year. In other words, a regression line fitted from multiple measurements is not significantly different from the rate of change estimated from initial and final readings only.

Some of these patients did exhibit a more rapid rate of decline in $\mathrm{FEV}_{1}$ than would have been expected. After deletion of outlying measurements, there were significant linear trends in $\mathrm{FEV}_{1}$ against time for 7 cases. The individual slope coefficients were: 19, 43, 44, 56, 70, 71 and $82 \mathrm{ml} /$ year. However, such limited numbers did not permit any meaningful further analysis.

\section{Discussion}

Lung function abnormalities were common in this series of patients with scleroderma, but were generally mild and did not progress. Severe impairment was confined to patients with respiratory symptoms. The prevalence of restrictive and obstructive defects was comparable to that found by Owens and Follansbee 1 (23\% and $16 \%$ respectively), but less than the $45 \%$ and $22 \%$ found by Peters-Golden et al. ${ }^{8}$

Progressive airflow obstruction and more severe lung restriction have been seen in smokers with scleroderma. ${ }^{15}$ Peters-Golden et al. ${ }^{16}$ found more rapid decline of vital capacity and $\mathrm{D}_{\mathrm{L}} \mathrm{CO}$ in former

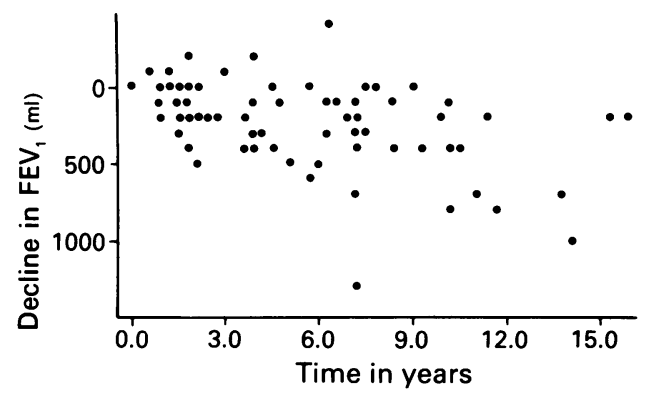

Figure 1 Longitudinal change in $\mathrm{FEV}_{1}$ for 19 subjects against time since first measurement. Note that the change from baseline is taken as zero at the outset for all cases. The following regression line was fitted: Decline in $\mathrm{FEV}_{1}(\mathrm{ml})=30+37 \times$ years. smokers. Unfortunately, the effect of smoking on change in lung function could not be meaningfully examined in the present series because of missing data and limited statistical power.

The failure to demonstrate significant decline in lung function might be a consequence of studying individuals long after the onset of scleroderma, thus missing an early marked change in gas diffusion or lung volumes. The inverse relationship between the duration of Raynaud's phenomenon and rate of change in VClends some support to this concept. However, a retrospective case series from New Zealand suggested that, on average, pulmonary fibrosis was not evident on chest X-ray until 8.5 years after the onset of Raynaud's phenomenon. ${ }^{6}$

Symptoms were related to spirometry, gas transfer and chest X-ray appearance rather than to rate of change in lung function variables. The presence of an interstitial pattern on chest X-ray was related to impaired baseline lung function as has been previously found, ${ }^{2}$ but not to the rate of change. The association between positive anti-centromere antibody and near normal spirometry is additional evidence that the presence of this antibody denotes milder disease. In general, ACA-positive patients have better survival and less extra-oesophageal disease than ACA-negative patients. ${ }^{17}$

Whilst patients with generalized skin involvement (Type 3) have a poorer prognosis, ${ }^{10}$ as a group they did not have worse lung function or a more rapid decline. It has long been known that localization of skin changes to the fingers does not imply absence of pulmonary involvement. ${ }^{2}$ Since half the cases in the present series had sclerodactyly alone (Type 1), some of the negative results could reflect selection bias for mild disease. A simple clinical classification is more practical than the sometimes arbitrary distinction between CREST and diffuse systemic sclerosis.

D-Penicillamine has been reported to lead to improvement in $\mathrm{D}_{\mathrm{L}} \mathrm{CO}$ amongst treated scleroderma patients. ${ }^{8}$ Unfortunately, it was not possible to examine meaningfully the effect of penicillamine on lung function in the present series. A formal randomized placebo-controlled double-blind trial of the drug was not conducted. Furthermore the treated patients received only $250 \mathrm{mg}$ over short periods of time. Medsger ${ }^{18}$ noted that retrospective studies suggested improvement in $\mathrm{D}_{\mathrm{L}} \mathrm{CO}$ but not vital capacity and called for a placebo controlled prospective study of D-penicillamine.

Impaired gas transfer had an adverse effect on survival and 3 of 4 patients with $\mathrm{D}_{\mathrm{L}} \mathrm{CO} \leqslant 40 \%$ predicted died, in accordance with a previous report. ${ }^{8}$ It should be noted that the majority of the deaths were not due to pulmonary disease. Unfortunately, changes in laboratory methods prevented estimation of the rate of change in gas transfer. In 
short, $\mathrm{D}_{\mathrm{L}} \mathrm{CO}$ is an important test in the initial assessment of scleroderma.

Calculations of change in FEV based on only two or three data points can vary markedly as a result of sensitivity to small survey biases. ${ }^{19}$ For the majority of subjects in the present retrospective study only two sets of spirometric values were available. Nonetheless the mean duration of follow-up was greater than the recommended minimum of 4 years. ${ }^{19}$ In the 19 subjects who had three or more measurements it has been shown that the difference between first and last measurements overestimated the true rate of longitudinal change in $\mathrm{FEV}_{1}$ with time. However, this methodological inaccuracy did not affect the conclusions. Neither the estimate from two measurements nor the true rate of change in $\mathrm{FEV}_{1}$ differed significantly from that seen in normal subjects.

The absolute annual rate of decline in VC in the present series was comparable to that experienced by normal subjects. However, one retrospective study of patients with scleroderma ${ }^{20}$ has reported an average decline in FVC of $100 \mathrm{ml} /$ year. The 38 patients were even more selected than the present series, $39 \%$ were black, $54 \%$ smoked and their initial lung function was much worse. These factors including the differences between VC and FVC in smokers are likely to account for the apparent discrepancy.

Retrospective case series are limited by the completeness of clinical records. This accounts for the variation in the total number of patients studied as shown in the various tables. There would seem to be a possibility of bias to retesting patients with more serious pulmonary involvement, but this would be unlikely to produce the generally negative findings reported here.

More valid results can be obtained by a prospective study of lung function in scleroderma patients. ${ }^{21}$ Vital capacity and $\mathrm{D}_{\mathrm{L}} \mathrm{CO}$ were found to decrease at rates greater than expected from crosssectional data. However, the mean rate of decline in VC $(51 \mathrm{ml} /$ year) was not significantly greater than that reported above. Sex, age, race and chlorambucil treatment did not significantly affect the rates of change. Whilst smokers demonstrated less change in total lung capacity and static lung compliance than nonsmokers, as above there was no significant difference in spirometric changes. Furthermore, a longer duration of symptoms was confirmed to be associated with slower rates of decline in lung volumes. As found above, the overall progression of lung disease was indolent, but there was considerable individual variability.

In conclusion, most scleroderma patients have abnormal lung function when first tested. It was confirmed that initial impairment of gas diffusion was associated with a poor prognosis. However, overall significant worsening of spirometry was not shown in this study. The lack of continued deterioration in lung function in scleroderma patients is further evidence that the disease does not inevitably progress. The name 'progressive' systemic sclerosis is a misnomer. It would appear that an initial documentation of lung function should be done in patients with scleroderma, but defining which cases warrant repeat testing awaits furthero prospective evaluation.

\section{Acknowledgements}

The authors thank Stephen Kershaw, Corrie Gardiner and Judy Roget for expert technical assistance, Dr Edmond Tai for his encouragement and Rachel Abramson for statistical advice. MJA held a National Health and Medical Research Council postgraduate research scholarship.

\section{References}

1. Owens, G.R. \& Follansbee, W.P. Cardiopulmonary manifestations of systemic sclerosis. Chest 1987, 91: 118-127.

2. Ritchie, B. Pulmonary function in scleroderma. Thorax 1964, 19: 28-36.

3. Medsger, T.A., Masi, A.T., Rodnan, G.P., Bedenek, T.G. \& Robinson, H. Survival with systemic sclerosis (scleroderma): a life table analysis of clinical and demographic factors in 309 patients. Ann Intern Med 1971, 75: 369-376.

4. Bagg, L.R. \& Hughes, D.T.D. Serial pulmonary function tests in progressive systemic sclerosis. Thorax 1979, 34, 224-228.

5. Colp, C.R., Riker, J. \& Williams, M.H. Serial changes in scleroderma and idiopathic interstitial lung disease. Arch Intern Med 1973, 132: 506-515.

6. Eason, R.J., Tan, P.L. \& Gow, P.J. Progressive systemic sclerosis in Auckland: a ten year review with emphasis on prognostic features. Aust NZ J Med 1981, 11: 657-662.
7. Ungerer, R.G., Tashkin, D.P., Furst, D. et al. Prevalence and clinical correlates of pulmonary hypertension in progressive systemic sclerosis. Am J Med 1983, 75: 65-74.

8. Peters-Golden, M., Wise, R.A., Hochberg, M.C. Stevens, M.B. \& Wigley, F.M. Carbon monoxide diffusing capacity as predictor of outcome in systemic sclerosis. Am J Med 1984, 77, 1027-1034.

9. Steen, V.D., Owens, G.R., Redmond, C., Rodnan, G.P. \& Medsger, T.A. The effect of D-penicillamine on pulmonary findings in systemic sclerosis. Arthritis Rheum 1985, 28: 882-888.

10. Barnett, A.J., Miller, M.H. \& Littlejohn, G.O. A survival study of scleroderma patients diagnosed over 30 years (1953-1983): the value of a simple cutaneous classification in the early stages of the disease. $J$ Rheumatol 1988, 15: 276-283. 
11. American Thoracic Society Statement - Snowbird workshop on standardisation of spirometry. Am Rev Respir Dis 1979, 119: $831-838$.

12. Cotes, J.E. Lung function - Assessment and Application in Medicine. 4th edition. Blackwell Scientific, Oxford, 1979, pp. 235-244, 365-387.

13. Ryan, T.A., Joiner, B.L. \& Ryan, B.F. Minitab Reference Manual. Duxbury Press, Boston, 1981, pp. 62-67, 87-97.

14. Colton, T. Statistics in Medicine. Little Brown \& Co., Boston, 1974, pp. 174-179, 131-142, 207-214.

15. Steen, V.D., Owens, G.R., Fino, G.J., Rodnan, G.P. \& Medsger, T.A. Pulmonary involvement in systemic sclerosis (scleroderma). Arthritis Rheum 1985, 28: 759-767.

16. Peters-Golden, M., Wise, R.A., Schneider, P., Hochberg, M., Stevens, M.B. \& Wigley, F. Clinical and demographic predictors of loss of pulmonary function in systemic sclerosis. Medicine 1984, 63: 221-231.

17. Miller, M.H., Littlejohn, G.O., Davidson, A., Jones, B. \& Topliss, D.J. The clinical significance of the anticentromere antibody. Br J Rheumatol 1987, 26, 17-21.
18. Medsger, T.A. D-Penicillamine treatment of lung involvement in patients with systemic sclerosis (scleroderma). Arthritis Rheum 1987, 30: 832-833.

19. Burrows, B., Lebowitz, M.D., Camilli, A.E. \& Knudson, R.J. Longitudinal changes in forced expiratory volume in one second in adults. Methodologic considerations and findings in healthy nonsmokers. Am Rev Respir Dis 1986, 133: 974-980.

20. Schneider, P.D., Wise, R.A., Hochberg, M.C. \& Wigley, F.M. Serial pulmonary function in systemic sclerosis. Am J Med 1982, 73, 385-394.

21. Greenwald, G.I., Tashkin, D.P., Gong, H. et al. Longitudinal changes in lung function and respiratory symptoms in progressive systemic sclerosis: a prospective study. Am J Med 1987, 83: 83-92. 